Article

\title{
Assessment of the road traffic air pollution in urban contexts: a statistical approach
}

\author{
Concettina Marino ${ }^{1 *}$, Antonino Nucara ${ }^{1}$, Maria Francesca Panzera ${ }^{1}$, Matilde Pietrafesa ${ }^{1}$ \\ 1 Department of Civil, Energy, Environmental and Material Engineering (DICEAM), “Mediterranea” \\ University of Reggio Calabria, Italy \\ * Correspondence: concettina.marino@unirc.it
}

\begin{abstract}
In the article a statistical approach to the assessment of the emission rates discharged by the road traffic in a spatial context is proposed. It exploits an indicator, the Yearly Average Vehicle, representing the pollutant emission rate of the average vehicle belonging to a specific category, and considers the statistical variability of most of the involved traffic parameters: vehicle speed and mileage travelled in the considered time period. Finally, indicators, assessing both the most probable value among the possible emission rates and the extent of their variability range, are proposed. They may also be used to underpin decision making-processes, when the effects of different policies addressing air pollution issues, are to be evaluated. Therefore, they are suitable for the analysis supporting urban planning activities, with a view to addressing and mitigating the effects and the consequences of pollution due to the transportation sector of the urban context.
\end{abstract}

Keywords: Road Traffic; Air Pollution Assessment; Emission factors; Statistical Approach, Transport Policy

\section{Introduction}

During the last years, many actions have been undertaken to reduce pollutant emissions both on the local and global point of view. European Union has always had a leading role towards this issue, with the aim of obtaining a low-carbon or zero-emission economy within 2050 [1].

To reach this aim, several actions need to be taken among the different pollutant sectors, including the civil, the industry and the transport one, promoting energy efficiency and a change of paradigm. The pillars of such concept rest on the use of renewable energy, a distributed energy generation (in all the sectors), the use of new fuels (hydrogen first) and new storage systems, also in the transportation sector (fuel cell vehicles, plug-in ones, etc.).

Even though some of the previous sectors have shown a significant reduction in their emissions, the transportation sector is the only one which conversely suffered an increase in its emissions $(+8 \%$ in 2016 referring to 1990) [2]. According to European Standards, transportation sector contributes to $27 \%$ of the total EU-28 greenhouse gas emissions; however, its emissions need to fall by around two thirds by 2050 in order to reach $-60 \%$ GHG reduction target, as set out in the Transport White Paper [3].

Within the sector, road transport represents more than $70 \%$ of the total [4], contributing significantly to global and local pollution, due also to the increasing number of vehicles and a large mobility enhancement. For this reason, many manufactures are working hard to respect Legislation limits, for example regarding the target of $\mathrm{CO}_{2}$ emissions $(\mathrm{g} / \mathrm{km})$, fixed at $95 \mathrm{~g} \mathrm{CO}_{2} / \mathrm{km}$ from 2020 for passenger cars [5].

In parallel, many authors have written about this issue, studying the influence of air pollution on air quality especially in urban areas [6,7] or on human health [8]; promoting different scenarios and projections to reduce GHG emissions [9-12]; considering the effect of new ecological vehicles in the vehicle fleet [13], etc. Others have researched the correlation among traffic parameters and pollutant concentration [14,15], and many models and methodologies have been proposed through the years: Fontaras et al. [16] studied a monitoring approach to estimate on-road $\mathrm{CO}_{2}$ emissions through vehicle simulation model; Kholod et al. [17] proposed a methodology for vehicle emission 
inventories in cities where limited data are available, estimating black carbon emissions; Fu, Kelly and Clinch [18] suggested a bottom-up methodology applicable for both nationally-aggregated data and spatially-disaggregated results, providing modelling parameters to support policy analyses; Ahmed et al. [19] evaluated the effectiveness of transport policies to reduce transport emissions in India, as Hasan, Chapman and Frame [20] did, analysing with a multi-criteria study the efficacy of the adopted policies in terms of transport emissions reduction.

Among the different methodology, the COPERT (COmputer Programm to calculate Emissions from Road Transport) one is the most known and used in the European Union [21], being a part of the EMEP (European Monitoring and Evaluation Programme)/EEA (European Environment Agency) air pollutant emission inventory guidebook [22], which is bases on IPCC guidelines [23]. The EMEP/EEA provides three different approaches (Tiers) to evaluate pollutant emissions, in function on the available data, starting from a simpler one (Tier 1) to a detailed procedure (Tier 3). In the last one, parameters like the vehicle speed and the average distance covered are considered, enabling the calculation of hot and cold emissions.

However, it is important to refer on-road emissions to real driving conditions and to the actual vehicle fleet [24], considering also the possible changes due to the future presence of modern vehicles, for example electric/hybrid vehicles or hydrogen ones [25-27].

Such information could be useful to local authorities and institution, providing information about the actual emissions of the running vehicle fleet in order to adopt the proper mobility and regulatory policies to reduce urban pollutant emissions.

Among the different methodologies, the authors have already proposed a procedure based on a unique emission factor for each category of vehicles, which takes in account all the specification belonging to a certain class. Specifically, referring to a fixed year, a Yearly Average Vehicle (YAV) has been introduced [12]. However, the results of the proposed procedure, based on the EMEP/EEA Tier 3 approach, still depends on two parameters which actually are statistical variables with different statistical distribution: the vehicle speed and the travelled distance.

In order to address this issue a new approach of the YAV is proposed, considering the statistical perspective. It was applied to the urban area of the city of Reggio Calabria, a city in the southern Italy, starting from its vehicle fleet composition data provided by the ACI (Automobile Club d'Italia) database [28].

\section{Methodology}

The approach of the proposed calculation procedure is based on the tier 3 method reported in the EMEP/EEA guidelines [22].

Specifically, the detailed tier 3 procedure, which combines technical data (emissions factors) and activity data (total vehicle $\mathrm{km}$ ), is used to asses a unique indicator capable of summarizing the emission features of the fleet, namely the Yearly Average Vehicle (YAV) [12]. This indicator is, in turn, exploited to take the statistical variability of the involved parameters (vehicle's speed and mileage) into account. Therefore, a probabilistic approach is proposed to asses exhaust emissions from road transport.

A description of the methodology is reported in the following sections.

\subsection{EMEP/EEA Tier 3 method}

According to this procedure, the hot exhaust emissions of each vehicle typology depend upon a set of factors, including the distance that each vehicle travels, its speed, and its features like age, engine size and weight. In addition, emission class stated by the reference technical legislation (namely the European Emission Standard), which each vehicle has to comply with, strongly influences the emission rate.

Therefore, the method is grounded on a classification of the vehicle sets which are categorized by type (cars, heavy vehicles, motorcycles, etc.), by fuel, by age, and by engine capacity or, with regard to commercial vehicles exclusively, also by weight. In this methodology, the age of the vehicle is used to identify the technical legislation (namely the European Emission Standard) ruling the 
emission rates when the vehicle was registered. Therefore, it is used to identify the emission technology of the vehicle, which in turn is referred to as "Euro Standard"

For each vehicle category c, emission factors (namely the mass of the specific pollutant which is emitted by the vehicle per path unit, expressed in grams of pollutant per vehicle and per kilometre, $\mathrm{g}$ vehicle $\mathrm{e}^{-1} \mathrm{~km}^{-1}$ ) are defined as a function of the vehicle speed:

$$
E F_{p, k}(v)=\frac{\alpha v^{2}+\beta v+\gamma+\frac{\sigma}{v}}{\varepsilon v^{2}+\zeta v+\eta}
$$

where $v$ is the journey average speed $(\mathrm{km} / \mathrm{h})$ of vehicle, subscript $p$ refers to the pollutant, $k$ the vehicle category (namely referred to the vehicle type - passenger car, heavy-duty vehicles, etc - the fuel, the engine volume or vehicle weight and the legislation emissive class identified by the age of the vehicle). The values of the coefficients $\alpha, \beta, \gamma, \sigma, \varepsilon, \zeta$ and $\eta$ are derived from EEA [22].

The emissions of the pollutant $p$, due to a given vehicle class for a daily time period, $E_{p, k}$, $\left(\mathrm{g} \mathrm{day}^{-1}\right)$ can be, hence, estimated by means of:

$$
E_{p, k}=E F_{p, k} \times N_{k} \times L_{k}
$$

where:

- $\quad N_{k}$ is the number of vehicles belonging to each homogeneous emitting class of the analysed fleet.

- $\quad L_{k}$ is the mileage travelled by the $k$-class vehicle in the considered time period $\left(\mathrm{km} \mathrm{day}^{-1}\right)$.

The total amount of the emissions of pollutant $p$ discharged by the all the type vehicles, in the analyzed spatial and temporal context, $E_{p}\left(\mathrm{~g} \mathrm{day}^{-1}\right)$, is given by:

$$
E_{p}=\sum_{k=1}^{N_{t}} E F_{p, k} \times N_{k} \times L_{k}
$$

where $N_{t}$ is the number of homogeneous subcategories which the category fleet can be subdivided into.

\subsection{The Yearly Average Vehicle}

The yearly average vehicle [12] is an emission factor function referred to an aggregated group of vehicles. Specifically, it is defined as the average emission factor of an aggregated group of vehicles circulating in a defined spatial and yearly context. Therefore, it can be referred to a type of vehicles or to the whole fleet.

Its analytical structure can be expressed as:

$$
Y A V_{p, c, v}(v)=\sum_{k}^{N_{c}} E F_{p, k}(v) \times S_{k}
$$

where:

- $\quad c$ is the category involving vehicles which are homogeneous from the point of view of the various factors influencing the hot exhaust emissions, involving the vehicle type (i.e., passenger cars, heavy duty vehicles, etc.), the distance that each vehicle travels, its speed, its age (related to the legislation emissive class), its engine size and its weight;

- $Y A V_{p, c, v}$ is the yearly average vehicle of the category $c$ (namely concerning the vehicle type, the fuel, the engine volume or vehicle weight and the legislation emissive class), for the pollutant $p$ (g vehicle $\mathrm{e}^{-1} \mathrm{~km}^{-1}$ ); it is a function of the vehicle speed $v$;

- $\quad N_{c}$ is the number of homogeneous subcategories which the category $c$ can be subdivided into;

- $S_{k}$ is the share of the $\mathrm{k}^{\text {th }}$ subcategory of vehicles within the category $c$.

Therefore, the emissions discharged by the whole category $c$ per mileage unit, $e_{p, c}\left(\mathrm{~g} \mathrm{~km}^{-1}\right)$ is:

$$
e_{p, c, v}(v)=N_{c, t o t} \times Y A V_{p, c}(v)
$$

where $N_{c, t o t}$ is the number of vehicles within the categories $c$.

As a consequence, assuming as a constant the daily mileage, $L_{c}\left(\mathrm{~km} \mathrm{day}^{-1}\right)$, travelled by the vehicles belonging to all the homogeneous subcategories of the category $c$, the emission amount which the category $c$ is accounted for is: 


$$
E_{p, c, v}(v)=N_{c, t o t} \times Y A V_{p, c}(v) \times L_{c}=e_{p, c}(v) \times L_{c}
$$

Finally, the emission of the whole fleet is:

$$
E_{p, v}(v)=\sum_{c=1}^{N} N_{c, t o t} \times Y A V_{p, c}(v) \times L_{c}
$$

where $N$ is the number of categories composing the whole fleet.

It is worth focusing attention on the fact that, in accordance to the procedure, the emission rate of the fleet can be assessed only when average values of the vehicle speed and travelled daily mileage are set.

\subsection{The stochastic approach}

The $Y A V$ is a function of the vehicle speed, which is a random variable like most of the traffic parameters. Therefore, in order to estimate the emissions due to the circulating fleet, the stochastic variability of the parameter should be taken into account through a distribution curve $f(v)$. In this stochastic approach, the mean value of the yearly average vehicle is given by:

$$
Y A V_{p, c}=\int_{0}^{v_{\max }} Y A V_{p, c, v}(v) f_{v}(v) d v
$$

where $f_{v}(v)$ is the probability density function of the speed of the vehicles belonging to the $c$ category and circulating in the examined spatial context.

Therefore, the emissions discharged by the whole category $c$ per mileage unit, $e\left(\mathrm{~g} \mathrm{~km}^{-1}\right)$ is:

$$
e_{p, c}=N_{c, t o t} \times Y A V_{p, c}
$$

where $N_{c, t o t}$ is the number of vehicles within the categories $c$.

As a consequence, the emission due to the whole category $c$ is:

$$
E_{p, c}=N_{c, t o t} \times Y A V_{p, c} \times L_{c}
$$

However, the estimation of the pollutant emissions from road transport does also require the knowledge of another random variable: the trip distance $L$, travelled by the vehicles in the considered time period (see eqs. (6), (7)).

If $f_{L}(L)$ is the probability density function of the variable $L$, eq. (10) allows the probability density function $f_{E}(E)$ of the variable $E$ to be calculated.

As a matter of fact, considering the theorem of change of variables of a probability density function, it yields:

$$
f_{E}(E)=f_{L}(L) \times \frac{d g^{-1}(E)}{d E}
$$

being:

$$
E=g(L)=N \times Y A V \times L
$$

with:

$$
L=g^{-1}(E)=\frac{E}{N \times Y A V}
$$

and as a consequence:

$$
\frac{d g^{-1}(E)}{d E}=\frac{1}{N \times Y A V}
$$

Substituting in equation (11), we obtain:

$$
f_{E}(E)=f_{L}(L) \times \frac{1}{N \times Y A V}
$$

This allows the cumulative distribution function to be calculated:

$$
F_{E}(\bar{E})=\int_{0}^{\bar{E}} f_{E}(E) d E
$$

As a matter of fact, it was stated that: 


$$
E=N \times Y A V \times L
$$

from which it can be derived that:

$$
d E=(N \times Y A V) d L
$$

and:

$$
\bar{E}=N \times Y A V \times \bar{L}
$$

Substituting in eq. (13) and considering eq. (12) we obtain:

$$
F_{E}(\bar{E})=\int_{0}^{\bar{L} \times N \times Y A V}\left[f_{L}(L) \times \frac{1}{N \times Y A V}\right] \times(N \times Y A V) d L
$$

that is:

$$
F_{E}(\bar{E})=\int_{0}^{\bar{L} \times N \times Y A V} f_{L}(L) d L
$$

This approach allows the assessment of emission percentiles, being:

$$
P(E \leq \bar{E})=F_{E}(\bar{E})
$$

where $P(E \leq \bar{E})$ is the probability that $E \leq \bar{E}$.

\section{An application}

The proposed methodology was applied to assess the emissions of the passenger car fleet of the Southern Italy city of Reggio Calabria which, in the considered reference year (2019) was made of 114,160 vehicles [29].

Specifically, five pollutants were taken into account: CO2, CO, NOx, VOC and PM; in addition, two scenarios were analyzed: the first one is the reference scenario and is referred to the passenger car fleet actually circulating in 2019, whereas the second one corresponds to the passenger cars that would circulate in 2030 in the hypothesis that from 2019 to 2030 every emissive category of the fleet would develop following the same linear trend as from 2009 to 2019 (Figure 1).

As a result, in 2030 the car fleet is composed of 119.368 vehicles.

The passenger car features in 2019 (reference year) and 2039 are reported in Figure 2 and Figure 3 , where the distributions by fuel type and emissive technology (emission standards) are depicted.

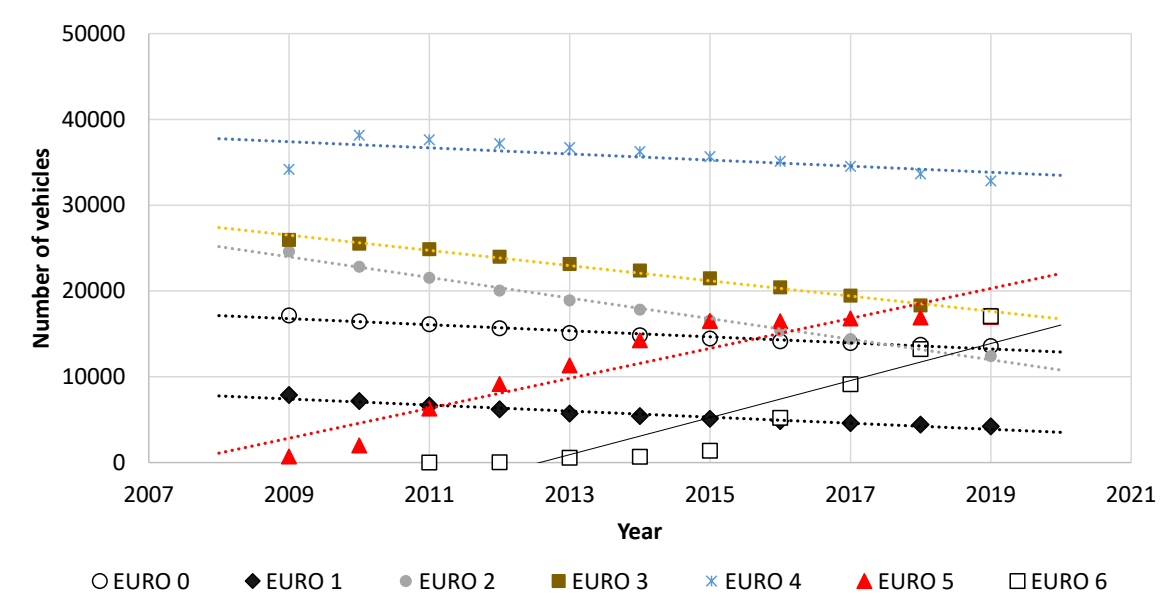

Figure 1. Emissive class trend development from 2009 to 2019. 

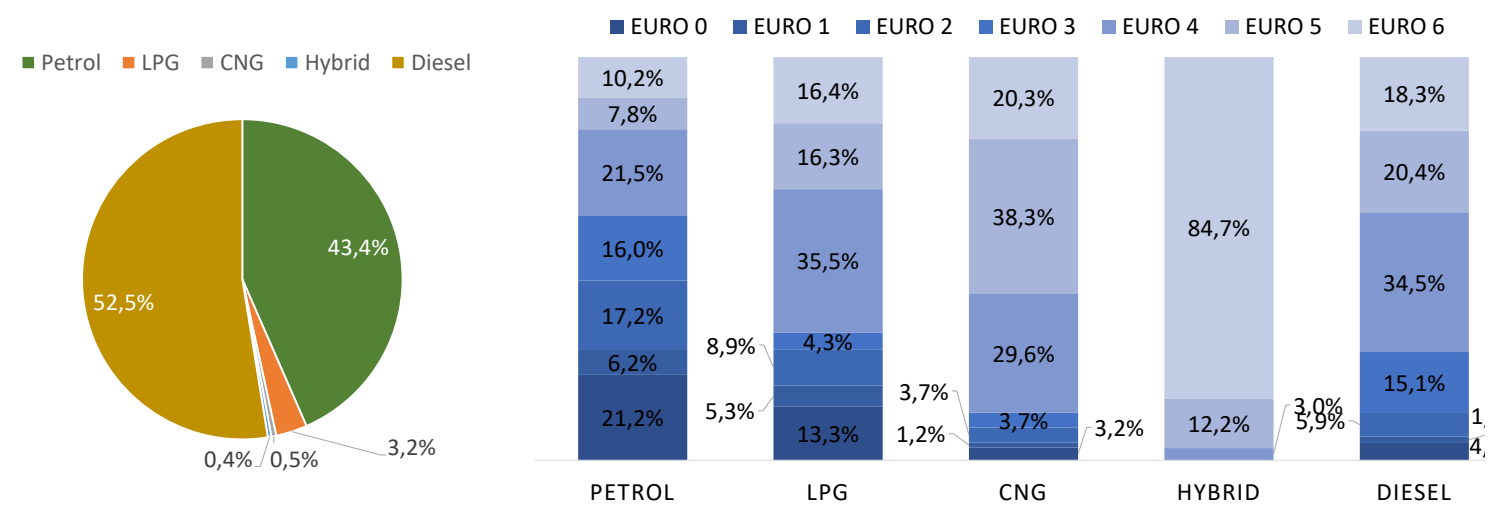

Figure 2. Passenger car fleet composition - reference year 2019.

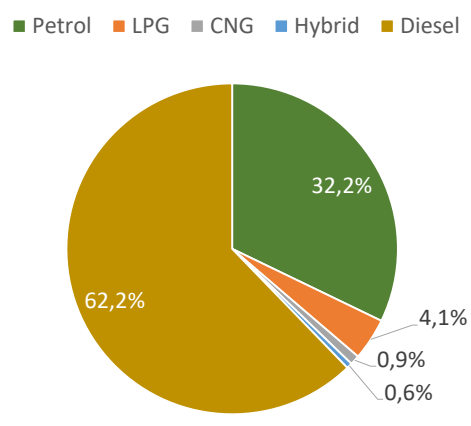

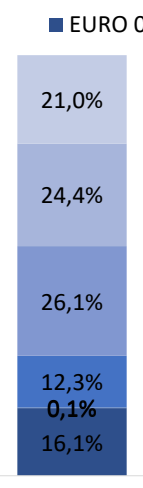

PETROL

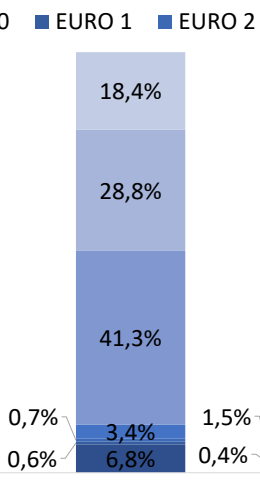

LPG

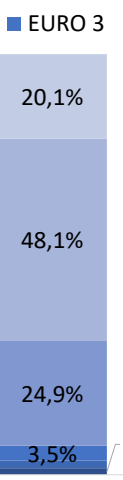

CNG

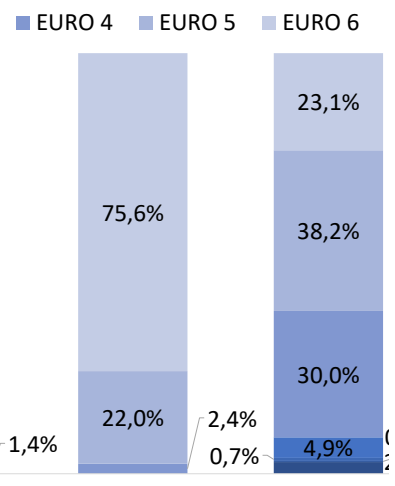

HYBRID

DIESEL

Figure 3. Passenger car fleet composition -year 2030.

As far as the frequency distribution of the vehicle speed, available studies propose different function forms especially in urban context [30]: a sum of two Gaussian plus an exponential [31] or a simple Gaussian [32] [33].

For the sake of simplicity, in the proposed application the Gaussian function was used, which demonstrated to be an acceptable fit in case of under-saturated flow [30], typical of the examined context .Therefore, the frequency distribution of the vehicle speed is:

$$
f_{v}(v)=\frac{1}{\sigma \sqrt{2 \pi}} e^{-\frac{\left(v-\mu_{v}\right)^{2}}{2 \sigma^{2}}}
$$

where:

- $\mu_{v}$ is the mean of the speed distribution $(\mathrm{km} / \mathrm{h})$

- $\sigma$ is the standard deviation of the speed distribution $(\mathrm{km} / \mathrm{h})$

On the other hand, the probability distribution of the distance travelled by passenger cars is of lognormal type [34] [35]:

$$
f_{L}(L)=\frac{1}{\sigma_{y} L \sqrt{2 \pi}} \times e^{-\frac{1}{2}\left[\left(\ln L-\mu_{y}\right) / \sigma_{y}\right]^{2}}
$$

where:

- $\mu_{y}$ is the mean of the y probability distribution, with $y=\ln L$,

- $\sigma_{y}$ is the standard deviation of the y probability distribution.

The mean and standard deviation of all the variables used to build up the probability distribution curves are reported in Table 1 [19]. 
Table 1. Mean and Standard deviation of the involved variable [19].

\begin{tabular}{ccc}
\hline Variable & Mean & Standard Deviation \\
\hline Speed $(\mathrm{km} / \mathrm{h})$ & 22.0 & 1.8 \\
Daily travelled distance $(\mathrm{km} /$ day $)$ & 32.4 & 5.4 \\
\hline
\end{tabular}

\section{Results}

In Figure 4 calculated YAVs with eq (8) for various pollutants and fuel types are reported. Both the 2019 scenario and its evolution outcome in 2030 are depicted.

The indicator account for the contribution to the specific pollutant emission of the average vehicle belonging to each considered category.

$\mathrm{CO2}$

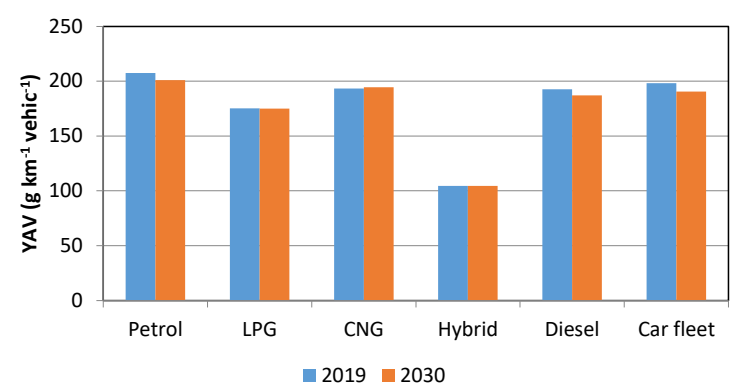

NOx

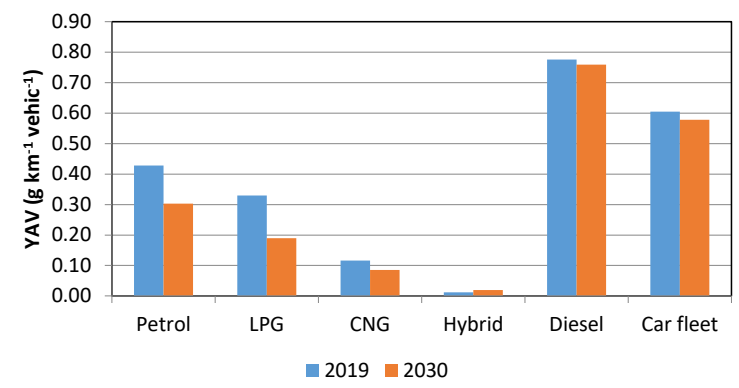

CO

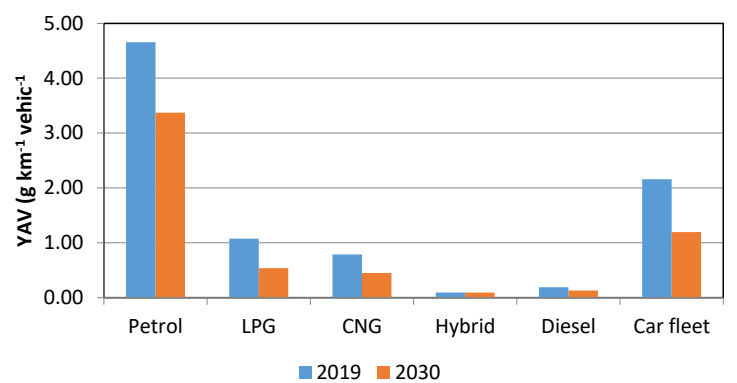

voc

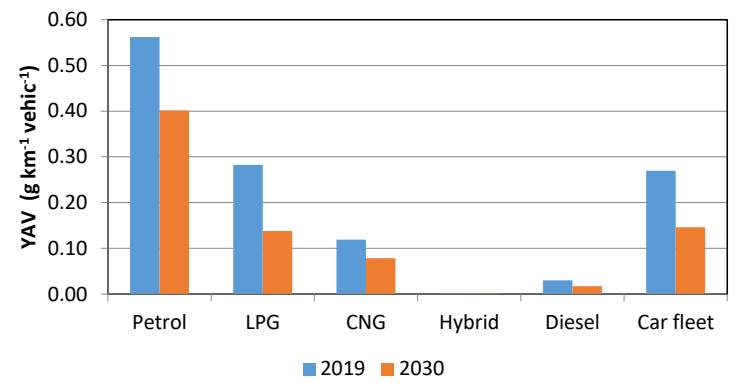

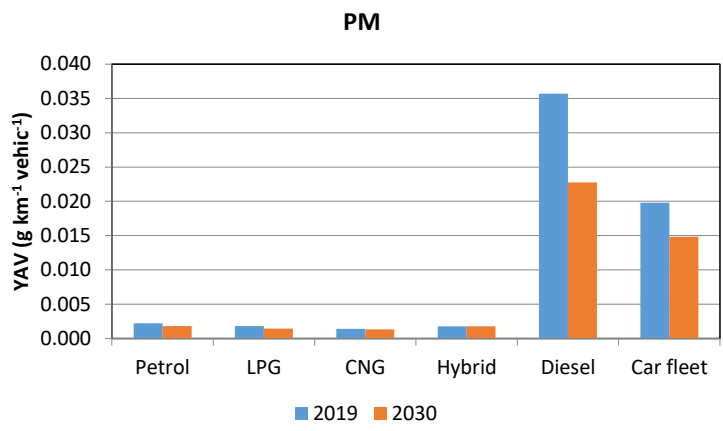

Figure 4. YAV for single pollutant and fuel type.

As a matter of fact, from Figure 4 it can be inferred that potentially, all the fuels have a remarkable impact in terms of $\mathrm{CO} 2$ emissions, whereas the petrol fueled average vehicle is responsible for the greatest contribution to both $\mathrm{CO}$ and VOC releases. On the contrary, the diesel fueled average vehicle is responsible for the highest NOx and PM productions. This information can be pivotal when actions changing the fleet composition are to be undertaken, so that decision-making process can be effectively guided. 
In this context, it is worth highlighting that, as far as hybrid vehicles are concerned, they have a small share within the car fleet $(0.07 \%)$, they are all of the full hybrid type, and hence the assessed specific emissions are related to the petrol contribution.

Considering the numerousness of the single category, the global emissions of the pollutant $p$, in 2019 and 2030, for fuel type $F$ and per unit path length, $e_{p, F}$ (eq. (9)), can be estimated.

The results are reported in Figure 5.

$\mathrm{CO} 2$

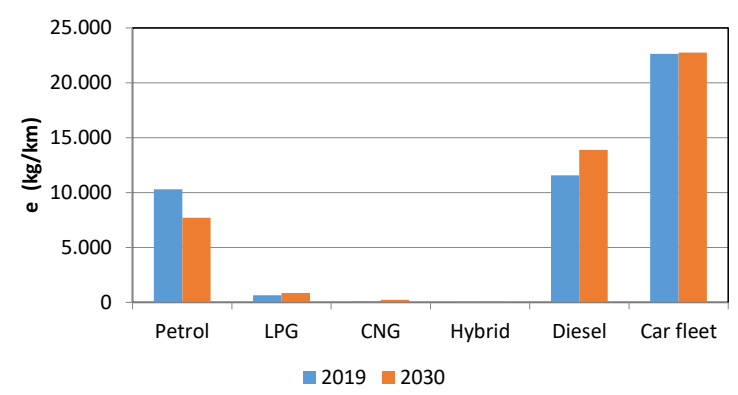

NOx

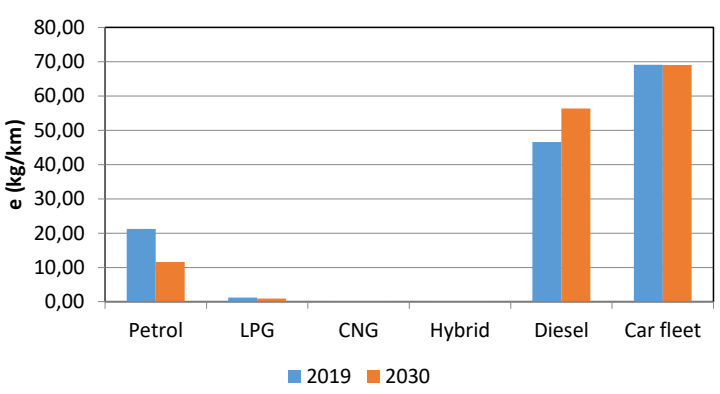

CO

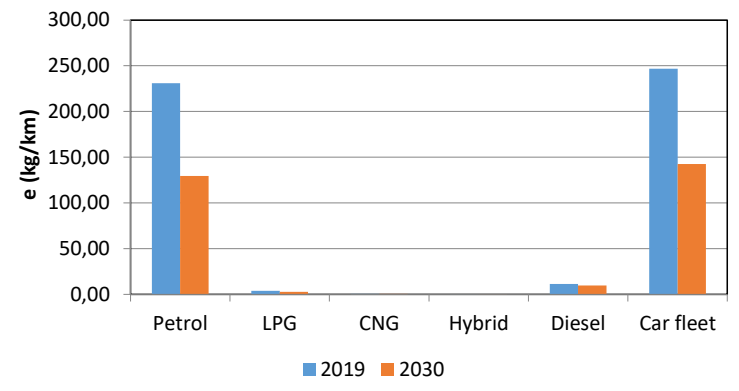

VOC

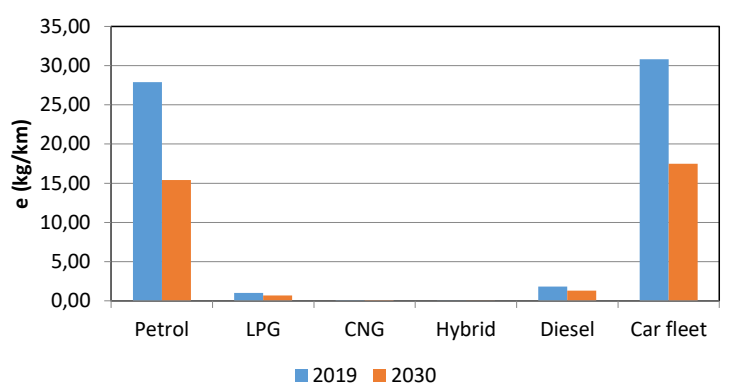

PM

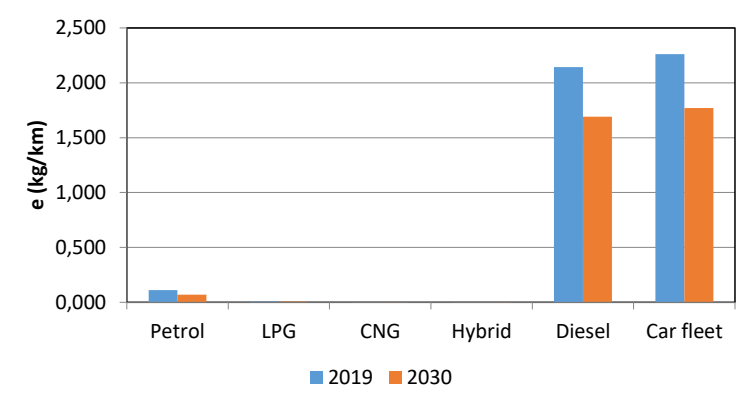

Figure 5. Emissions for single pollutant, fuel type and unit of path length.

In this case, the contribute of every whole vehicle category to the passenger car fleet emissions can be inferred. Specifically, given the share of both petrol and diesel passenger cars in the fleet composition (Figure 2), major emissions are due to these types of vehicle. Therefore, the impact of the numerousness of each category can be appreciated.

From this perspective, it is worth underlining that, despite the increased number of vehicles occurred within the fleet from 2019 to 2030, the increase in the share of the less emissive classes (Figure 2 and Figure 3), which also takes place during the same period of time, produces a reduction of the discharged pollutant emission rates. In other words, this is the outcome generated by the improvement of the whole passenger car fleet emissive quality.

When the mileage probability density distribution (eq. (18)) is considered and eq. (12) is applied, the probability density function $f_{E}(E)$ depicted in Figure 6 can be inferred. It is referred to the whole 
fleet, under the hypothesis that the probability density function of the variable $L, f_{L}(L)$, is the same for all the vehicle categories composing the fleet.

This is a sufficiently reliable hypothesis for the analyzed context, which concerns a small town where, owing to homogeneous demographic factors and reduced transport options, the features of the passenger car daily path are quite uniform for the various vehicle categories

Figure 6 shows that, as the passenger car fleet evolves from year 2019 to year 2030, the probability density distributions of $\mathrm{CO}, \mathrm{VOC}$ and PM emission rates $(E)$ change appreciably, shifting towards smaller values of $E$ and less disperse shapes. This testifies an improvement of the vehicle emissive quality over time.
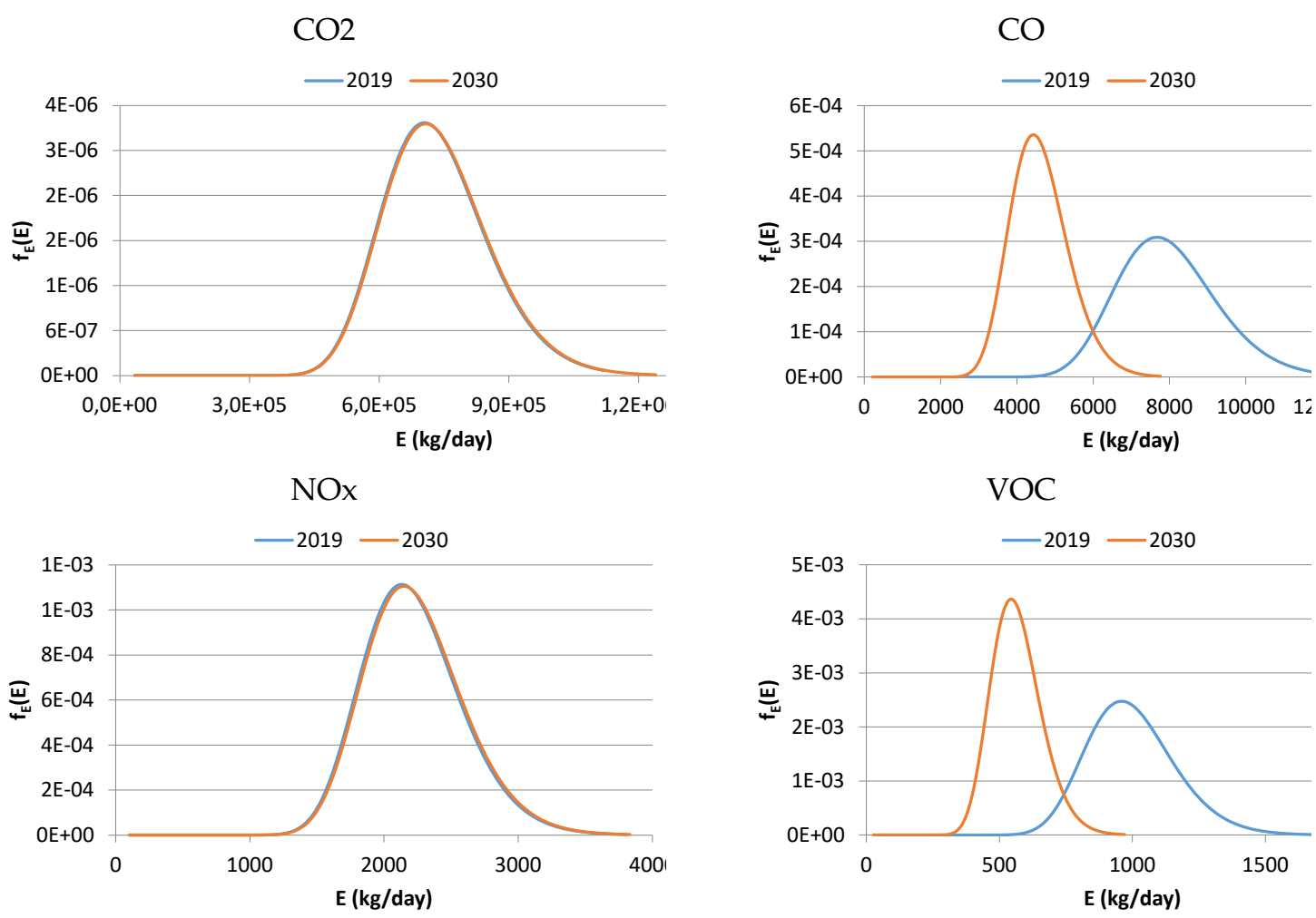

PM

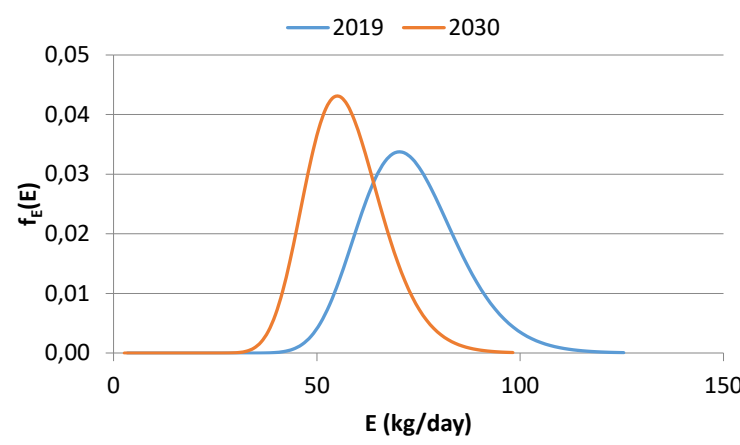

Figure 6. Emission probability density function for single pollutant.

Similar conclusions can be drawn analyzing the trend of the percentiles P95 and P5, namely the emission rates which have a probability of $5 \%$ and $95 \%$ to be overcome. They are calculated by means of eq. (15)(13) and allow the variability range of each pollutant emission rate to be estimated (Figure 7). As a matter of fact, it is delimited by the P95 and P5 values and involves the emission rates values which are characterized by an occurrence probability higher than 5\% and lower than 95\%.

It can be noted that the range of probable values of emission rates shrinks for CO, VOC and PM, as the car fleet evolves from 2019 to 2030 and the share of the most emissive vehicle categories tends to decrease. 
$\mathrm{CO2}$

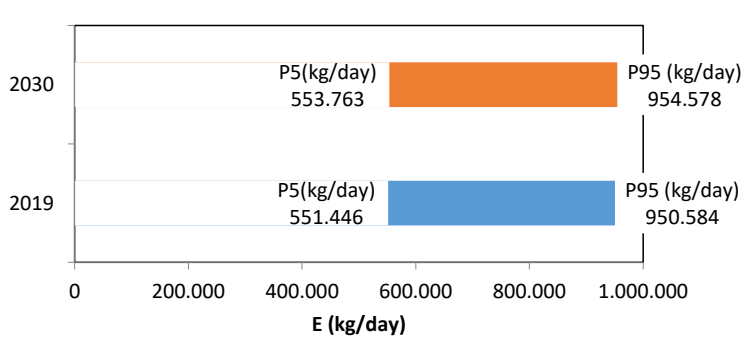

NOx

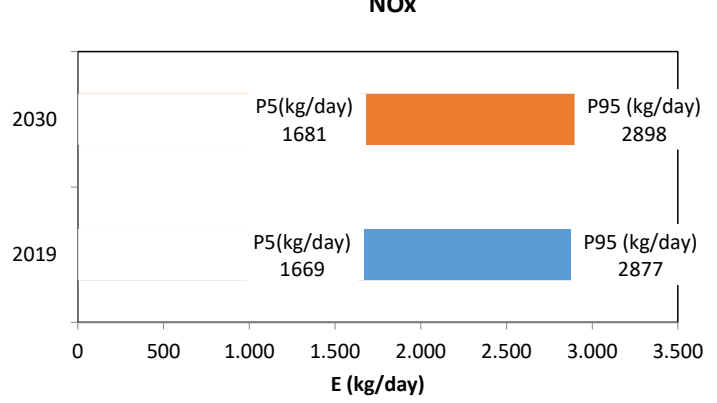

CO

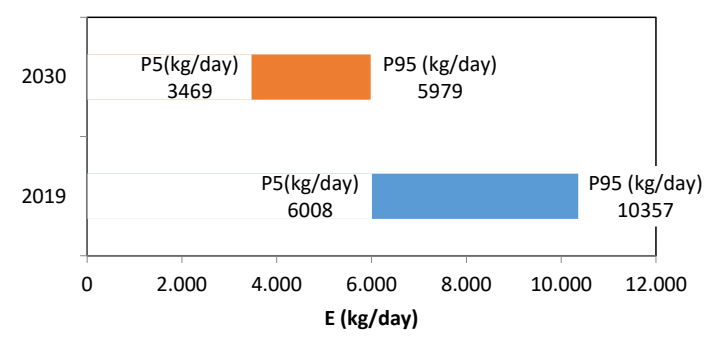

VOC

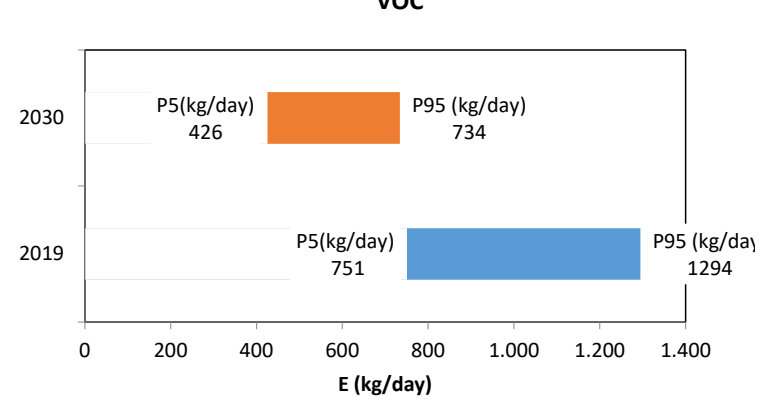

PM

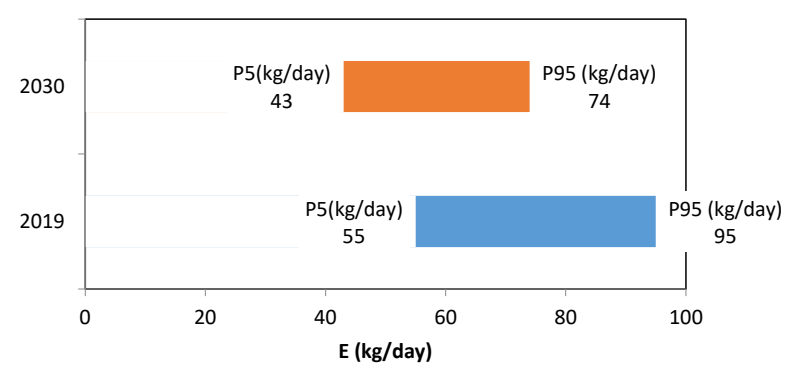

Figure 7. Emission rate percentiles P90 and P10 for each considered pollutant.

As far as the emission rate most probable value is concerned, Figure 8 reports the mode of the variable, which is the value with the highest probability of occurrence. It decreases in 2030 for all the considered pollutants.

In conclusion, both the P5-P95 variability range and the emission rate modal value can be exploited to analyze the trend of the car park development from the emission rate perspective.

They can underpin the decision-making process, when the effect of different actions or measures altering the features, composition and size of the circulating fleet is to be assessed. 
$\mathrm{CO} 2$

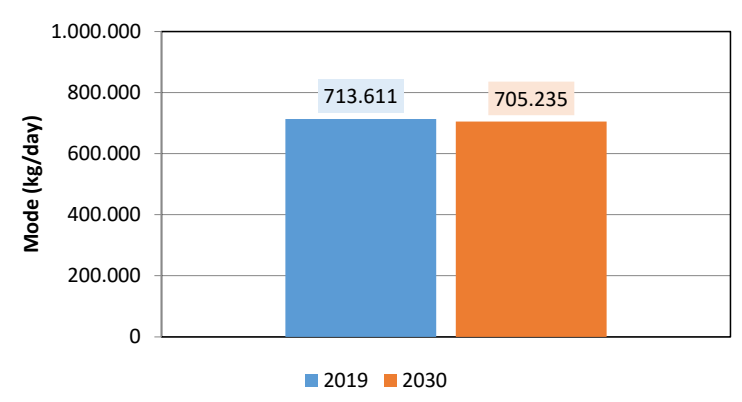

NOx

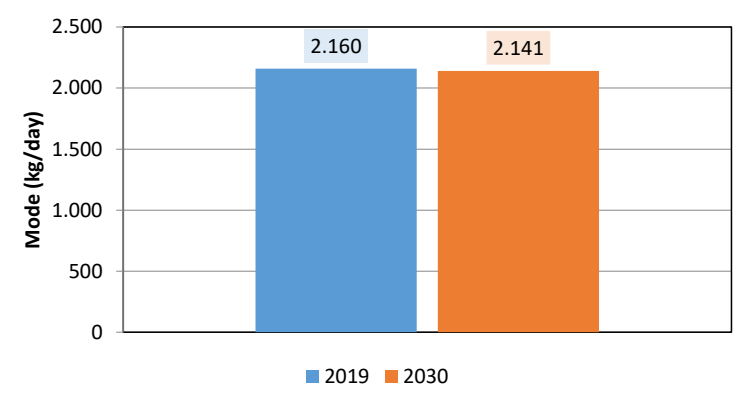

CO

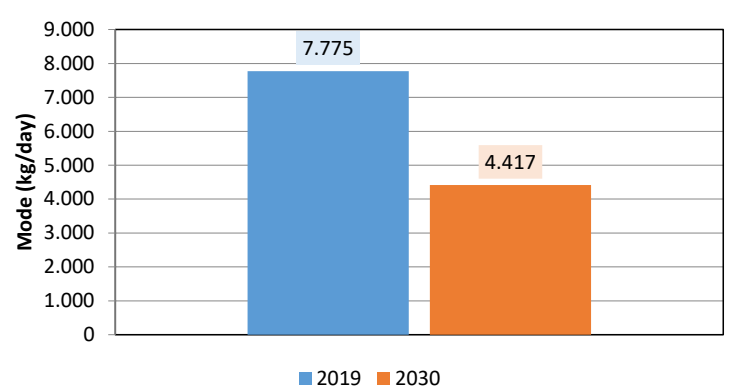

VOC

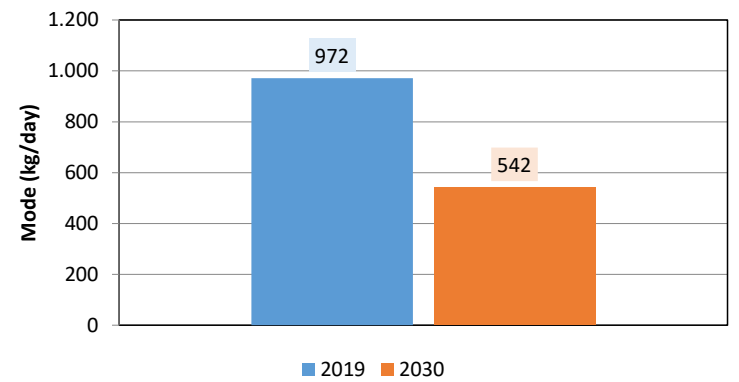

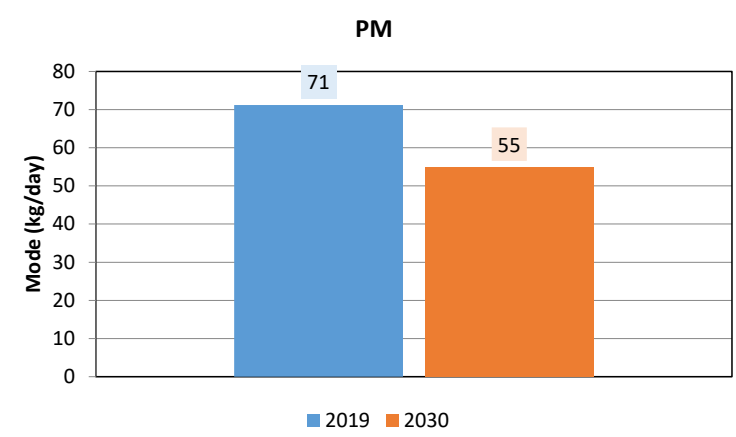

Figure 8. Modal value of each considered pollutant emission rate distribution.

\section{Conclusions}

The analysis of the global amount of pollutant emissions released by road traffic is a crucial aspect of the planning actions aimed at mitigating air pollution and greenhouse gas emissions, especially in urban settlements which are deemed to be among the human activities which exert the most deeply spoiling impacts on the environment.

From this point of view, mobility planning may play a pivotal role; however, to reach the objective, it should entail methods and procedures capable of estimating road traffic emission rates by means of indicators measuring the impact which each envisaged action may have on the improvement of the air quality.

In this context, a method for the assessment of the pollutant emission rate due to the road traffic was proposed. It involves a statistical approach and, therefore, it is capable of considering the influence of traffic parameters which are characterized by a statistical variability: vehicle speed and length of the travelled route in a specific period of time.

The outcome of the proposed procedure consists in a set of indicators which allows different aspects of the involved phenomena to be estimated. These indicators regard: the pollutant emissions of the average vehicle of the fleet (YAV) referred to whole range of possible speed values; the 
emission rate per mileage unit; the most probable emission rate considering the statistical variability of the distance travelled by each vehicle; the extent of the variability range of the possible emission rate values.

All the indicators can be referred to the whole fleet or to a single homogeneous category, depending on either the type of performed analysis or the vehicle fleet features. In addition, each indicator is related to a single pollutant.

The method was applied to a case study, so that an account was given of its suitability in assessing the effects of the evolution of the passenger car fleet in a medium size city located in Southern Italy, according to a possible scenario.

Author Contributions: The co-authors had together equally contributed to the completion of this article. Conceptualization, C.M., A.N., M.F.P.; Data curation, M.F.P; Methodology, C.M., A.N., M.F.P.; Software, M.F.P.; Formal Analysis, C.M., A.N.; Writing-original draft, C.M.; Writing-review and editing, A.N., M.P.; Validation, C.M., A.N., M.F.P. and M.P.; Supervision, M.P.

All authors have read and agreed to the published version of the manuscript.

Conflicts of Interest: The authors declare no conflict of interest.

\section{References}

1. European Commission Long-term low greenhouse gas emission development strategy of the EU and its Member States Available online: www.roadmap2050.eu (accessed on Apr 2, 2021).

2. European Environment Agency National emissions reported to the UNFCCC and to the EU Greenhouse Gas Monitoring Mechanism Available online: https://www.eea.europa.eu/data-andmaps/indicators/transport-emissions-of-greenhouse-gases-7/assessment (accessed on Apr 20, 2021).

3. European Commission Roadmap to a Single European Transport Area - Towards a competitive and resource efficient transport system; 2011;

4. European Commission Transport emissions. A European Strategy for low-emission mobility Available online: https://ec.europa.eu/clima/eu-action/transport-emissions_en (accessed on May 5, 2021).

5. European Parliament; Council of the European Union Regulation (EC) no. 443/2009. Off. J. Eur. Union 2009, 140, 1-15.

6. Cariolet, J.-M.; Colombert, M.; Vuillet, M.; Diab, Y. Assessing the resilience of urban areas to traffic-related air pollution: Application in Greater Paris. Sci. Total Environ. 2018, 615, 588-596, doi:10.1016/j.scitotenv.2017.09.334.

7. Basagaña, X.; Triguero-Mas, M.; Agis, D.; Pérez, N.; Reche, C.; Alastuey, A.; Querol, X. Effect of public transport strikes on air pollution levels in Barcelona (Spain). Sci. Total Environ. 2018, 610-611, 1076-1082, doi:10.1016/j.scitotenv.2017.07.263.

8. Mueller, N.; Rojas-Rueda, D.; Basagaña, X.; Cirach, M.; Cole-Hunter, T.; Dadvand, P.; Donaire-Gonzalez, D.; Foraster, M.; Gascon, M.; Martinez, D.; et al. Urban and Transport Planning Related Exposures and Mortality: A Health Impact Assessment for Cities. Environ. Health Perspect. 2017, 125, 89-96, doi:10.1289/EHP220.

9. Jamshidi Kalajahi, M.; Khazini, L.; Rashidi, Y.; Zeinali Heris, S. Development of Reduction Scenarios Based on Urban Emission Estimation and Dispersion of Exhaust Pollutants from Light Duty Public Transport: Case of Tabriz, Iran. Emiss. Control Sci. Technol. 2020, 6, 86-104, doi:10.1007/s40825-019-00135-0.

10. Yang, L. Wang, Y. Lian, Y. Han, S. Factors and scenario analysis of transport carbon dioxide emissions in rapidly-developing cities. Transp. Res. Part D Transp. Environ. 2020, 80.

11. Krause, J.; Thiel, C.; Tsokolis, D.; Samaras, Z.; Rota, C.; Ward, A.; Prenninger, P.; Coosemans, T.; Neugebauer, S.; Verhoeve, W. EU road vehicle energy consumption and CO2 emissions by 2050 - Expertbased scenarios. Energy Policy 2020, 138, 111224, doi:10.1016/j.enpol.2019.111224.

12. Marino, C.; Nucara, A.; Pietrafesa, M.; Pudano, A. The Assessment of Road Traffic Air Pollution by Means of an Average Emission Parameter. Environ. Model. Assess. 2016, 21, 53-69, doi:10.1007/s10666-015-9489-8.

13. Li, J.; Jiao, J.; Tang, Y. Analysis of the impact of policies intervention on electric vehicles adoption considering information transmission - based on consumer network model. Energy Policy 2020, 144, 111560, doi:https://doi.org/10.1016/j.enpol.2020.111560. 
14. Romero, Y.; Diaz, C.; Meldrum, I.; Arias Velasquez, R.; Noel, J. Temporal and spatial analysis of traffic Related pollutant under the influence of the seasonality and meteorological variables over an urban city in Peru. Heliyon 2020, 6, doi:10.1016/j.heliyon.2020.e04029.

15. Wang, Z.; Zhou, H.; Si, Y.; Li, Y. Role of Traffic Emission on Temporal and Spatial Characteristics of Pollutant Concentration on Urban Road Network: A Case of Beijing. J. Adv. Transp. 2020, 2020, doi:10.1155/2020/8883697.

16. Fontaras, G.; Zacharof, N.; Doulgeris, S.; Myrsinias, I.; Toumasatos, Z.; Dimaratos, A.; Samaras, Z.; Kolokotronis, D.; Dornoff, J.; Mock, P. A Methodology for Monitoring On-Road CO 2 Emissions Compliance in Passenger Vehicles. In Proceedings of the CO2 Reduction for Transportation Systems Conference; SAE International, 2020.

17. Kholod, N.; Evans, M.; Gusev, E.; Yu, S.; Malyshev, V.; Tretyakova, S.; Barinov, A. A methodology for calculating transport emissions in cities with limited traffic data: Case study of diesel particulates and black carbon emissions in Murmansk. Sci. Total Environ. 2016, 547, 305-313, doi:https://doi.org/10.1016/j.scitotenv.2015.12.151.

18. Fu, M.; Kelly, J.A.; Clinch, J.P. Estimating annual average daily traffic and transport emissions for a national road network: A bottom-up methodology for both nationally-aggregated and spatially-disaggregated results. J. Transp. Geogr. 2017, 58, 186-195, doi:https://doi.org/10.1016/j.jtrangeo.2016.12.002.

19. ISFORT $17^{\circ}$ Rapporto sulla mobilità degli italiani [in Italian]. 2020, 172.

20. Hasan, M.A.; Chapman, R.; Frame, D.J. Acceptability of transport emissions reduction policies: A multicriteria analysis. Renew. Sustain. Energy Rev. 2020, 133, 110298, doi:https://doi.org/10.1016/j.rser.2020.110298.

21. Emisia S.A. COPERT - COmputer Programme to calculate Emissions from Road Transport. 2021.

22. European Environment Agency EMEP/EEA air pollutant emission inventory guidebook 2019: Technical guidance to prepare national emission inventories; 2019;

23. Intergovernmental Panel on Climate Change (IPCC) IPCC guidelines for national greenhouse gas inventories. Hayama: Intergovernmental Panel on Climate Change; Institute for Global Environmental Strategies (IGES), 2006; ISBN 4-88788-032-4.

24. André, M.; Pasquier, A.; Carteret, M. Experimental determination of the geographical variations in vehicle fleet composition and consequences for assessing low-emission zones. Transp. Res. Part D Transp. Environ. 2018, 65, 750-760, doi:https://doi.org/10.1016/j.trd.2018.10.005.

25. Weger, L.B.; Leitão, J.; Lawrence, M.G. Expected impacts on greenhouse gas and air pollutant emissions due to a possible transition towards a hydrogen economy in German road transport. Int. J. Hydrogen Energy 2021, 46, 5875-5890, doi:https://doi.org/10.1016/j.ijhydene.2020.11.014.

26. Schiffer, M.; Klein, P.S.; Laporte, G.; Walther, G. Integrated planning for electric commercial vehicle fleets: A case study for retail mid-haul logistics networks. Eur. J. Oper. Res. 2021, 291, 944-960, doi:10.1016/j.ejor.2020.09.054.

27. Stasinopoulos, P.; Shiwakoti, N.; Beining, M. Use-stage life cycle greenhouse gas emissions of the transition to an autonomous vehicle fleet: A System Dynamics approach. J. Clean. Prod. 2021, 278, 123447, doi:https://doi.org/10.1016/j.jclepro.2020.123447.

28. Automobile Club d'Italia (ACI) Open Data: Autoritratto Anno 2019; 2019;

29. ACI - Atomobile Club d'Italia Rappresentazione del parco veicolare italiano (In Italian) Available online: https://www.aci.it/laci/studi-e-ricerche/dati-e-statistiche/autoritratto (accessed on Apr 10, 2021).

30. Maghrour Zefreh, M.; Török, Á. Distribution of traffic speed in different traffic conditions: An empirical study in budapest. Transport 2020, 35, 68-86, doi:10.3846/transport.2019.11725.

31. European Commission's Joint Research Centre (JRC) Individual mobility: From conventional to electric cars; 2015;

32. Berry, D.; Belmont, D. Distribution of vehicle speeds and travel times. Proc. Second Berkeley Symp. Math. Stat. Probab. 1951, 589-602.

33. Street, S.J. Journal of the Eastern Asia Society for Transportation Studies, Vol.9, 2011. 2011, 9, 1558-1571.

34. Di Silvestre, M.L.; Riva Sanseverino, E.; Zizzo, G.; Graditi, G. An optimization approach for efficient management of EV parking lots with batteries recharging facilities. J. Ambient Intell. Humaniz. Comput. 2013, 4, 641-649, doi:10.1007/s12652-013-0174-y.

35. Qian, K.; Zhou, C.; Allan, M.; Yuan, Y. Modeling of Load Demand Due to EV Battery Charging in Distribution Systems. IEEE Trans. Power Syst. 2011, 26, 802-810, doi:10.1109/TPWRS.2010.2057456. 
